A PRODUÇÃO DE CURRÍCULOS

MULTICULTURAIS E DECOLONIAIS NO CURSO DE PEDAGOGIA PELO CINEMA NEGRO DE ZÓZIMO BULBUL

THE PRODUCTION OF MULTICULTURAL AND DECOLONIAL CURRICULUMS IN THE PEDAGOGY COURSE BY THE BLACK CINEMA OF ZÓZIMO BULBUL

\section{LA PRODUCCIÓN DE} CURRÍCULOS MULTICULTURALES $Y$ DECOLONIALES EN EL CURSO DE PEDAGOGÍA POR EL CINE NEGRO DE ZÓZIMO BULBUL
Resumo: Este artigo tem por objetivo apresentar a reconstrução de conhecimentos outros no curso de Pedagogia por meio do cinema negro de Zózimo Bulbul ao propor a exibição e a produção de atividades baseadas no filme Alma no olho. A fundamentação teórica respaldou-se no Paradigma Multicultural e nas Pedagogias decoloniais com o intuito de desenvolver conhecimentos para as diversidades enunciadas por meio do docente e dos estudantes participantes. As metodologias utilizadas foram a Pesquisa-ação e a Análise Criativa. Ao final, a investigação evidenciou a construção de conhecimentos propiciados pelas inter-relações corpóreas, estéticas e históricas do filme com as percepções e vivências dos graduandos.

Palavras-chave: Cinema negro. Formação de professores. Paradigma multicultural. Pedagogia decolonial.

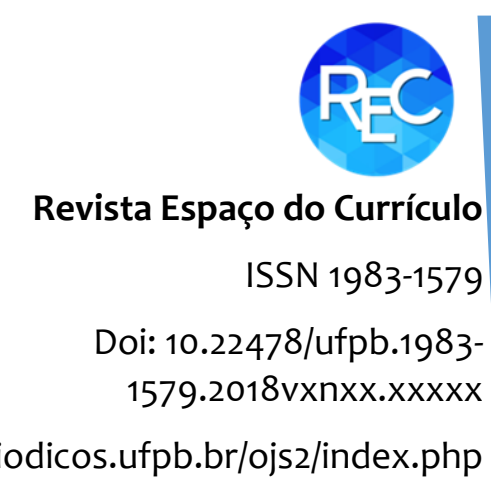

http://periodicos.ufpb.br/ojs2/index.php
Fabio Jose Paz Rosa

Doutor em Educação

Professor da Universidade Estácio de Sá, Brasil.

E-mail: fabiojp83@yahoo.com.br

Orcid: https://orcid.org/0000-0003-0672$191 X$.

Como citar este artigo:

ROSA, F. J. P. A PRODUÇÃO DE CURRÍCULOS MULTICULTURAIS E DECOLONIAIS NO CURSO DE PEDAGOGIA PELO CINEMA NEGRO DE ZÓZIMO BULBUL. Revista Espaço do Currículo, v. 14, n. 1, p. 1-16, 2021. ISSN2177-2886. DOI: https://doi.org/10.22478/ufpb.1983$1579.2021 \mathrm{v} 14 \mathrm{n} 1.54573$. 
Abstract: This article aims to present the reconstruction of other knowledge in the Pedagogy course through the black cinema of Zózimo Bulbul by proposing the exhibition and production of activities based on the film Alma no Olho. The theoretical foundation was supported by the Multicultural Paradigm and Decolonial Pedagogies in order to develop knowledge for the diversities enunciated by the participating teacher and students. The methodologies used were Action Research and Creative Analysis. In the end, the investigation showed the construction of knowledge provided by the corporeal, aesthetic and historical interrelationships of the film with the perceptions and experiences of the students.

Keywords: Black cinema. Teacher training. Multicultural paradigma. Decolonial pedagogy.

Resumem: Este artículo tiene como objetivo presentar la reconstrucción de otros saberes en el curso de Pedagogía a través del cine negro de Zózimo Bulbul proponiendo la exhibición y producción de actividades basadas en la película Alma no Olho. El fundamento teórico fue apoyado por el Paradigma Multicultural y las Pedagogías Decoloniales con el fin de desarrollar conocimientos para las diversidades enunciadas por el docente y alumnos participantes. Las metodologías utilizadas fueron Investigación Acción y Análisis Creativo. Al final, la investigación mostró la construcción de conocimientos que brindan las interrelaciones corporales, estéticas e históricas de la película con las percepciones y vivencias de los estudiantes.

Palavras-clave: Cine negro. Formación de professores. Paradigma multicultural. Pedagogía decolonial. 1 INTRODUÇÃO

A produção de currículos fundamentados nas diferenças tem sido uma prática e uma exigência nas legislações pensadas pelos movimentos sociais. Vislumbramos essa demanda na promulgação da Lei 10.639/2003 a partir da obrigatoriedade do ensino de Cultura e História afro-brasileira e africana nos currículos da educação básica, posteriormente reatualizada pela Lei 11.645/2008 ao incluir as histórias e culturas das populações indígenas.

Muito além da simples valorização dessas culturas, essas legislações provocaram os educadores brasileiros a repensarem os conhecimentos curriculares construídos, produzidos e reescritos por diversos grupamentos questionadores das perspectivas eurocêntricas. Em grande parte, o Movimento Negro $(M N)$ foi o responsável por ser um dos pedagogos nas relações políticas e sociais (GOMES, 2017, p. 10). Nesse afã, o MN tem a capacidade de ensinar à escola e à formação de professores conhecimentos outros para que as diferenças sejam constatadas no processo de ensino e aprendizagem.

Em consonância com essa perspectiva, esta pesquisa desenvolvida no processo do doutorado em educação, almejou pensar-praticar os conhecimentos curriculares da formação de professores através de uma das expressividades do MN: o Cinema negro. Para isso, fundamentamo-nos nos paradigmas multiculturais por meio da Pesquisa-ação com o intuito de desenvolver currículos decoloniais para a construção de conhecimentos pautados nos conhecimentos e saberes afro-brasileiros e africanos.

Em um primeiro momento, apresentaremos as perspectivas multiculturais como forma de repensar os conhecimentos produzidos na formação docente através do cinema negro de Zózimo Bulbul. Para isso, inter-relacionamos o Paradigma multicultural e os estudos decoloniais à metodologia da Pesquisa-ação e da Análise criativa nas produções didáticas de uma disciplina sobre multiculturalismo e educação inserida em um curso de Pedagogia de uma universidade federal. A proposta de pesquisa foi apresentada anteriormente ao regente por meio de dois planos de aula articulados à ementa da disciplina. Participaram das atividades, além do professor, cerca de doze estudantes em dois encontros nas duas últimas semanas do mês de junho de 2018.

A segunda parte do artigo analisa o curta-metragem Alma no olho (1973), roterizado, dirigido, produzido e interpretado por Zózimo Bulbul, enquanto reconstrução corpórea, estética e histórica das epistemologias afro-brasileiras.

A terceira parte apresenta as análises criativas dos estudantes e do regente da disciplina sobre multiculturalismo e educação posicionando-os em suas corporeidades, estéticas e histórias na produção do conhecimento curricular da disciplina cerne da pesquisa. 


\section{PARADIGMAS MULTICULTURAIS PARA PENSAR-PRATICAR CURRÍCULOS DECOLONIAIS.}

Apesar da Lei 10.639/2003 ter dezessete anos de implantação, muitas pesquisas (GOMES, JESUS, 2013; GOMES, 2012) demonstram ainda tensões, avanços e limites com descontinuidades de práticas pedagógicas antirracistas em algumas regiões brasileiras enquanto outras conseguem efetivar trabalhos pedagógicos mais consistentes, principalmente aqueles inseridos em contextos mais afirmativos e democráticos. Essas últimas obtêm resultados mais satisfatórios quando possuem gestões escolares, projetos políticos pedagógicos e formações continuadas fundamentadas nas temáticas étnico- raciais (GOMES; JESUS, 2013).

$\mathrm{Na}$ contramão do que muitas instiutições escolares já desenvolviam, os atuais documentos curriculares como a Base Nacional Curricular Comum (BNCC) e a Base Nacional Comum para a formação inicial de Professores da Educação Básica (BNC- Formação) pouco demonstram o interesse em tornar os currículos escolares e da formação docente fundamentados nos conhecimentos produzidos pelas diversidades étnico-raciais.

As lacunas da BNCC do Ensino Fundamental estão evidentes quando se defende as diversidades culturais por meio da existência de 250 línguas faladas no Brasil, inclusive aquelas preservadas pelas culturas afro-brasileiras e indígenas ainda desconhecidas da população brasileira. Mas que línguas são essas? Quem são os responsáveis por preservá-las e transmiti-las às futuras gerações?

Em Dezembro de 2017 foi enviada uma carta ao presidente da comissão da BNCC, César Callegari, solicitando respostas às contribuições das mais importantes entidades educacionais desconsideradas no debate da terceira e última versão do documento. Entre as instituições estavam a Associação Nacional pela Formação dos Profissionais da Educação (ANFOPE), a Associação Nacional de Política e Administração da Educação (ANPAE), a Associação Nacional de Pós-Graduação e Pesquisa em Educação (ANPEd), Associação Brasileira de Currículo (ABdC), o Centro de Estudos Educação e Sociedade (CEDES) e o Fórum Nacional de Diretores de Faculdades, Centros de Educação e Equivalentes das Universidades Públicas Brasileiras (FORUMDIR).

Em Julho de 2018, a ABdC reiterou os posicionamentos da carta interinstitucional do ano anterior por meio de nota ao qual afirmou a impossibilidade da BNCC em exaurir as disputas em torno do currículo. Para a associação, a tentativa de padronização dos currículos "constituem um vício insanável da BNCC" (ABdC, 2018). Esse também tem sido o posicionamento da Associação Brasileira de Pesquisadores Negros (ABPN) e do Grupo de Trabalho (GT) 21 - Educação e Relações étnico-raciais da ANPED que têm promovido encontros para debater as implicações da BNCC aos conhecimentos defendidos nas Diretrizes curriculares nacionais para a educação étnico-racial e história e cultura afro-brasileira.

A BNC-Formação, aprovada em Dezembro de 2019, ao propor revisar as Diretrizes Curriculares Nacionais para a formação inicial de professores em nível superior, busca adequá-la aos princípios e objetivos da BNCC. Para se ter ideia, as duas vezes em que surge o termo "étnico-racial" nesse documento é para fazer menção às formas de combater a violência física e simbólica sem maiores fundamentações curriculares e didáticas. Logo, A BNCC e a BNC-Formação reiteram o apagamento das epistemologias produzidas pelas histórias e culturas afro-brasileiras capazes de aproximar professores e estudantes das suas ancestralidades.

Ao contrário disso, pensar-praticar currículos com e pelas diferenças é comprometer-se com políticas educacionais cujas fundamentações sejam as existências dos próprios sujeitos da escola pública a partir de suas singularidades (MACEDO, RANNIERY, 2018). Esse desafio tensiona a formação inicial dos professores, para que o ensino e a aprendizagem referentes às questões étnico-raciais possam se consolidar enquanto campo do conhecimento.

No caso desta pesquisa, consideramos a necessidade primeira de evidenciar essas singularidades por meio das diferenças, sensibilizando os formadores de professores e os graduandos por meio dos conhecimentos produzidos pelos pensadores, cientistas e artistas afro-brasileiros e africanos. Consideramos essa perspectiva fulcral para a atuação de futuros docentes comprometidos com as diferentes relações produzidas pelas culturas afro-diaspóricas no contexto da sala de aula. Por isso, 
dialogamos com os paradigmas multiculturais. Stuart Hall (2003, p. 52) nos lembra que o termo multicultural:

[d]escreve as características sociais e os problemas de governabilidade apresentados por qualquer sociedade na qual diferentes comunidades culturais convivem e tentam construir uma vida em comum, ao mesmo tempo em que retém algo de sua identidade "original".

O microespaço de uma sala de aula pode ser compreendido por uma comunidade multicultural capaz de congregar estudantes caracterizados por vários aspectos como raça, gênero e classe social. Ao mesmo tempo, essa diversidade origina problematizações acerca das identidades situando cada um dos estudantes no contexto de formação. Com o intuito de compreender a construção do conhecimento entre o comum e as diferenças, desenvolvemos uma pesquisa de produção de outros conhecimentos através do Cinema negro de Zózimo Bulbul no curso de Pedagogia de uma universidade federal em uma disciplina eletiva sobre multiculturalismo e educação.

Nascido em 21 de setembro de 1937 no Rio de Janeiro, onde viveu até sua morte, ocorrida em 24 de janeiro de 2013, Zózimo Bulbul foi um dos mais importantes cineastas brasileiros a reconceituar a estética negra na sétima arte brasileira a partir da década de 1970. Antes, Bulbul atuou nas principais obras do Cinema Novo como em Pedreira de São Diogo (1962), de Leon Hirszman, que contava a história de pobreza vivida pelos negros habitantes dos morros da cidade do Rio de Janeiro. Em Compasso de espera (1969), de Antunes Filho, Zózimo interpreta seu primeiro protagonista, o poeta Jorge, par romântico da jovem branca de classe média Christina, interpretado por Renée de Vielmond. Nesse longa-metragem, a cinematografia brasileira discute pela primeira vez questão do negro na classe média.

A decisão em produzir seus próprios filmes ocorre após suas experiências como ator em diversas obras do Cinema Novo, pois Bulbul analisou ainda a ausência de personagens negros interpretando seus conhecimentos e subjetividades fundamentados nas ancestralidades africanas e afro-diaspóricas. Alma no olho (1973) com duração de 11 minutos é o primeiro filme do cineasta carioca com a intencionalidade de resgatar o memorial africano no antes, durante e após os processos escravocratas. Esse foi o filme filme escolhido para ser exibido, analisado e reconstruído por meio de atividades curriculares e didáticas com o professor e os estudantes participantes desta investigação.

Pelo fato de a pesquisa desenvolver-se em uma disciplina eletiva formada por estudantes não apenas da Pedagogia, mas também de Comunicação Social, História, Psicologia, Artes e Geografia, consideramos essa diversidade como mais um aspecto favorável à produção de novos conhecimentos por meio do curta-metragem Alma no olho (1973). Diante dessa realidade, procuramos desde o início chamar a atenção dos estudantes para a visão multicultural, pois essa conceituação "passa pela sensibilização à diversidade cultural dos professores-formadores-autores-pesquisadores, que constroem/transmitem o conhecimento na área educacional, assim como dos futuros professores e dos estudantes que vão interagir". (CANEN, 2008, p. 300). Nessa perspectiva, o multiculturalismo "obriga os educadores a reconhecer as estreitas fronteiras que moldaram e ainda hoje moldam como o conhecimento é partilhado em sala de aula" (HOOKS, 2013, p. 54).

Ao inter-relacionarmos diferentes metodologias, nos referenciamos em Canen e Ivenicki (2016) ao apresentarem quatro dimensões para o desenvolvimento de pesquisas multiculturalmente orientadas. A primeira é a "sensibilização à diversidade cultural dos próprios formadores-pesquisadores" (CANEN; IVENICKI, 2016) para assim construir e transmitir os conhecimentos em diversas áreas curriculares. No caso dessa pesquisa, almejamos desenvolver o reconhecimento do regente da turma e dos estudantes nos processos de produções corpóreas, estéticas e históricas despertadas por meio do contato com a cinematografia de Zózimo Bulbul.

De forma efetiva, a inter-relação entre diferentes metodologias como a Pesquisa-ação (THIOLLENT, COLETTE, 2014; BARBIER, 2007) e Análise Criativa (BERGALA, 2008) foram importantes para o reconhecimento da diversidade cultural capaz de romper com as barreiras curriculares (CANEN, IVENICKI, 2016) no processo de investigação. 
Thiollent e Colette (2014) problematizam sobre a formação de professores enquanto espaço que deve estar em sintonia com as diversidades indígenas, quilombolas, rurais, de gênero e de vulnerabilidade social. Por isso, a pesquisa-ação é uma metodologia adaptável às situações vivenciadas e aos interesses dos participantes. Entre diferentes formatos, a pesquisa-ação pode ser desenvolvida por meio de “oficinas com participação de professores em formação" (THIOLLENT, COLETTE, 2014, p. 214). No caso desta pesquisa, esta metodologia possibilitou aos participantes o reconhecimento da diversidade, a inserção dos próprios sujeitos no processo de formação, bem como na produção de conteúdos e procedimentos potencializadores dos saberes africanos e afro-diaspóricos.

Além da aquisição de novos conhecimentos por meio dos conhecimentos produzidos pelos movimentos sociais, "a pesquisa-ação educacional interfere no processo pedagógico e na elaboração do currículo" (THIOLLENT, 2014, p. 211). Nesse sentido, essa metodologia possibilitou-nos dimensionar tanto ao regente da disciplina quanto aos seus estudantes em pesquisadores de suas teorizações e práticas pedagógicas durante o processo de construção e reconstrução dos conhecimentos por meio das imagens cinematográficas.

A segunda dimensão em uma pesquisa multiculturalmente orientada de acordo com Canen e Ivenicki (2006) é a pluralidade de paradigmas que "matizam, mesclam e sintetizam contribuições de áreas diversas em perspectivas trans e interdisciplinares" (CANEN e IVENICKI, 2016, p. 41). Essa dimensão foi compreendida nesta pesquisa propondo a cinematografia de Zózimo Bulbul compondo o currículo de uma disciplina eletiva do curso de Licenciatura em Pedagogia buscando inter-relações nos conceitos de Multiculturalismo, decolonialidades, cinema e educação. Dessa forma, os participantes das aulas poderiam relacionar os conhecimentos adquiridos na disciplina com o filme Alma no olho, bem como nas Análise criativas e na produção de planos de aula fundamentados em perspectivas multiculturais e decoloniais.

Bergala (2008) apresenta a análise de criação não como uma finalidade em si, mas como passagem para outro momento em que a imaginação do espectador elabora

[...] o retorno ao momento imediatamente anterior à inscrição definitiva das coisas, em que as múltiplas escolhas simultâneas estavam quase atingindo o ponto de serem decididas: o último ponto em que os possíveis estavam abertos [...] ( BERGALA, 2008, p. 130)

Esse último ponto ainda não encerrado é onde o espectador pode encontrar outras possibilidades de imagens e sons de um filme reelaborado pelos seus sentidos. As possíveis escolhas estéticas, em suas multiplicidades de cores, oralidades, vestimentas têm um caráter pedagógico e dialógico com o ato de filmar (BERGALA, 2008). A Análise criativa é atravessada pela sensibilidade, mas também de racionalidade na busca de ressignificações pelas imagens. No caso dos licenciandos-espectadores, o exercício do olhar possibilita romper com a sedução das imagens desumanizantes e colonizadoras para assim produzir imagens outras (HOOKS, 2018).

Bergala (2008) denomina essas outras escolhas e as maneiras como podemos reposicioná-las de intuição determinada pelo corpo. Dessa forma, as escolhas criativas de um espectador podem ser primeiramente uma elaboração da corporeidade em que se pensa como determinadas imagens e sons estabelecem relações com os seus sentidos.

Essa perspectiva de Bergala se relaciona nesta pesquisa ao propor aos licenciandos colocarem em cena suas corporeidades por meio de suas falas e gestos e expressões. Em diálogo com a metodologia da Pesquisa-ação, a criatividade amplia as possibilidades de educadores e educandos para compreenderem melhor os processos de ensino e aprendizagem (THIOLLENT, COLETTE, 2014).

A terceira dimensão de pesquisas multiculturais defende a favorecimento da diversidade cultural promovida por diferentes embates. Interessou-nos nessa concepção compreender entre as exibições fílmicas e as Análises criativas, a produção de problematizações acerca dos conhecimentos construídos entre os diferentes sujeitos participantes da pesquisa. Nesse sentido, os graduandos construiam e reconstruiam as imagens negras por meio do filme exibido, analisado e reconceituado didaticamente no 
plano de aula produzido em grupo. Para compreender as diferentes pluralidades de acordo com os paradigmas multiculturais com vista à produção de conhecimentos em consonância com os estudantes negros participantes da pesquisa, dialogamos com os Estudos Decoloniais.

As pedagogias decoloniais, consoante Walsh (2009), são produzidas em diferentes espaços como escolas, universidades, nos bairros, nas comunidades, nos movimentos sociais e na rua. Por isso, a teorização dos conhecimentos decoloniais mobilizam os sujeitos a colocarem em xeque e intervirem com o objetivo de insurgir novas formas de existências relacionadas aos poderes e saberes da própria vida (WALSH, 2009). Esses posicionamentos suscitam a produção de novos conceitos fundamentados na intelectualidade negra e indígena (MIRANDA e RIASCOS, 2016).

Estamos pensando este conceito teórico-metodológico como uma forma dos estudantes negros e não negros produzirem epistemologias afro-brasileiras e africanas em consonância com suas futuras práticas docentes

[...] que nos permitam experiências curriculares expedicionárias capazes de influir nas "desaprendizagens" que, na atualidade, empurram as portas das instituições educacionais sustentadas, ainda, por orientações eurocêntricas das práticas pedagógicas. (MIRANDA, 2013, p. 103)

Nesse sentido, como podemos trazer ao currículo conhecimentos ainda não aprendidos que nos ensinem a desaprender? Miranda (2013) afirma a existência de uma constante pedagogia produzida no campo midiático produtora de "recomposições epistêmicas" (MIRANDA, 2013, p. 102) fundamentadas nos conhecimentos afro-diaspóricos. Dessa forma, é preciso suscitar "novos letramentos para recolocarmos a dimensão humana como ponta de lança para uma cultura, uma linguagem, um pensamento que abrigue estratégias sensíveis" (MIRANDA, 2013, p. 103).

Apesar das relações de poder presentes na elaboração do currículo escolar estar em constantes negociações entre políticas educacionais, didáticas e cotidianos, Miranda (2013) considera a formação de professores/as inserida em realidades dissonantes capazes de dificultar a produção de dialogias interculturais. Essa constatação se deve principalmente pelo fato da escola ser um espaço frágil disputado por diferentes poderes de caráter mais administrativo do que linguístico. (MIRANDA, 2013). Diante dessa necessidade de produzir outros currículos fundamentados nas vivências e existências de estudantes e professores, consideramos o Cinema negro como uma potente linguagem capaz de fazer enunciar inovadores conhecimentos pela sensibilidade.

A corporeidade é o primeiro espaço de reconhecimento da sensibilidade afro-diaspórica. A partir dos nossos corpos nos colocamos no mundo buscando diversas referências em grande parte elaboradas pelas fontes audiovisuais. Quando os conhecimentos corpóreos e estéticos são compreendidos enquanto existência é possível também reelaborar a própria escrita histórica das populações afrobrasileiras e diaspóricas.

Em uma perspectiva decolonial, a corporeidade conduziu a câmera de Bulbul para fazer- se presença e constituir conhecimentos e saberes em que os sujeitos tenham compreensão da sua existência no mundo. Assim, já podemos vislumbrar em Alma no olho (1973) o ensinar a ver a corporeidade negra quando o próprio Zózimo se coloca nas interpretações de várias personagens na trajetória dos povos africanos e afro-brasileiros. Dessa forma, Zózimo pôs-se a ensinar com sua própria corporeidade.

Ter uma consciência corporal na produção de conhecimentos é essencial para compreender o processo de ensino associado aos espaços e tempos em que os sujeitos vivem. Essas diferentes relações corpóreas entre professores das licenciaturas e os estudantes nos levam a problematizar que

[o] arranjo corporal de que estamos falando desenfatiza a realidade de que os professores universitários estão na sala de aula para dar algo de si para os alunos. O mascaramento do corpo nos encoraja a pensar que estamos ouvindo fatos neutros e objetivos, fatos que não dizem respeito à pessoa que partilha a informação. Significativamente, aqueles entre nós que estão tentando criticar os 
preconceitos na sala de aula foram obrigados a voltar ao corpo para falar sobre si mesmo como sujeitos da história. (HOOKS, 2014, p. 186)

Encontrar a corporeidade para ensinar permite voltar ao estado de presença no corpo (hooks, 2014) para reconhecer as populações cujos conhecimentos foram retirados da sala de aula. A corporeidade presentificada está inserida em uma Pedagogia engajada, onde os professores aproximam-se cada vez mais do conhecimento como prática da liberdade e se afastam da espetacularização equivocadamente confundida com a ideia de uma boa aula.

Por último, o paradigma multicultural visa verificar se as organizações "estão abertas à pluralidade e a diversidade ou, ao contrário, são impermeáveis às mesmas" (CANEN e IVENICKI, 2016, p. 48). Nesse sentido, a perspectiva multicultural não é apenas objeto de estudo, mas visa incentivar aos futuros pesquisadores a valorização da "pluralidade cultural” (CANEN e IVENICKI, 2016, p. 48).

Dessa forma, analisamos como as temáticas suscitadas pelos filmes de Bulbul poderiam contribuir para professores e alunos desenvolverem pensamentos, conhecimentos e didáticas cujas diferenças corpóreas, históricas e estéticas africanas e afro-brasileiras fundamentem tanto os processos de ensino quanto de aprendizagem no espaço de formação docente.

A responsabilidade dos formadores de professores em reconceituar os saberes antes inquestionáveis da cultura e da ciência por meio das epistemologias negras é um dos primeiros passos a serem tomados para sensibilizar e despertar os estudantes para a aprendizagem com e pelas imagens relacionadas às suas existências.

No caso dos licenciandos negros, as imagens evidenciadas na cinematografia negra podem produzir diferentes concepções de reconhecimento das opressões existentes e a aquisição de conhecimentos corpóreos, estéticos e históricos ressignificadores das suas existências. Os licenciandos pardos podem fazer o questionamento a partir dos aspectos da cinematografia negra posicionando-se às suas negritudes, pois historicamente esses são ensinados a não reconhecerem as condições que os aproximam do eurocentrismo e os afastam da ancestralidade afro-brasileira.

Aos licenciandos não negros, a cinematografia negra pode contribuir para pensar o lócus de privilégio histórico-social. Dessa forma, muitos poderão compreender como eles são capazes de se colocar em escuta aos ensinamentos das populações afro-brasileiras para ampliar suas relações consigo e com o mundo em um posicionamento desierárquico de ideias muitas vezes privilegiadores somente dos conhecimentos produzidos pela cultura eurocêntrica em detrimento aos produzidos pelas culturas diaspóricas.

\section{ANÁLISE DO CURTA-METRAGEM ALMA NO OLHO}

Alma no olho (1973) apresenta Zózimo Bulbul narrando a trajetória das populações negras representando várias personagens entre liberades e opressões por meio da expressividade corporal. Durante os 11min de filme, destaca-se o contraste da cor preta da pele de Bulbul no fundo totalmente branco. Na apresentação do título vemos um plano desfocado escuro, com letras cursivas brancas enunciando o título da obra fílmica: ALMA NO OLHO.

No segundo plano, acima dos olhos da primeira personagem interpretada por Bulbul, surge nome da música africana acompanhante de todas as performances do filme: Kulú se mama. De autoria do percussionista e cantor Juno Lewis, a canção compõem uma das músicas do álbum produzido por John Coltrane, de 1965.

Aos poucos a câmera se afasta do rosto de Bulbul e visualizamos apenas seus olhos. O som de um tambor se enuncia e o enquadramento da câmera foca no rosto do ator e diretor do filme juntamente aos créditos, ocupando desde a testa até abaixo do seu nariz. Enquanto surgem sons de tambores, os olhos do ator são direcionados para a esquerda e direita e finalmente olham em direção à câmera. Volta a explorar o seu olhar diferentes sentidos quando um corte de plano passa para uma imagem inferior do rosto, mostrando do nariz até o queixo. Nesse momento, é enunciada a dedicatória do filme ao saxofonista negro estadunidense John Coltrane. 
O próximo plano mostra o enquadramento do sorriso da primeira personagem em seguida transformada em gargalhada. A câmera parece adentrar no interior da boca onde a língua da personagem movimenta-se lentamente, como se estivesse sentindo o sabor de algo pela primeira vez. Com uma voz baixa, Juno Lewis balbucia uma canção infantil lembrando o ato de ninar uma criança. Logo um corte abre para um plano oblíquo e depois lateral do seu rosto. A personagem agora parece gargalhar com a boca bem aberta.

Esta primeira personagem interpretada por Bulbul é o de um homem que está nascendo e reconhece sua existência. Assim, a câmera se detém na orelha, no perfil dos ombros e do pescoço. Corta para um plano do rosto, interrompido pelo movimento das mãos cruzando sua fronte. Ele sorri. Os detalhes dos primeiros planos nos dão a evidência de levar ao público reconhecer essa personagem por toda a possível expressividade corporal. Assim, a personagem nasce e como uma criança toca o seu corpo sem receios ou olhares punitivos de outras pessoas.

Os sons dos tambores retornam e enunciam cada uma das partes do corpo juntamente com o vocal doce e calmo de Juno Lewis. Em seguida, um plano mostra a imagem das axilas e parte do rosto e outro plano acompanha o suor escorrendo de suas axilas. As imagens nos intrigam. $O$ suor enquanto substância vem do interior do organismo, associando-se ao interior da alma impregnada nos olhos do espectador.

Um novo plano sequencia várias partes do corpo de Bulbul: o lado direito das costas, ombro, rosto, peito, axila, uma mão que se abre lentamente do lado do peito, cujo pelo se confunde imediatamente com o do púbis e por último suas nádegas.

Um corte de plano nos leva a ver seus pés em movimento, quase ensaiando uma corrida sem sair do lugar. $O$ ritmo da suposta marcha aumenta juntamente com a música de Coltrane ao fundo. A voz e o instrumento aumentam a intensidade rítmica juntamente ao lado esquerdo do corpo de Bulbul. A personagem só pode expressar liberdade e alegria.

Aos 3min15seg, adentra o som do saxofone de Coltrane contrapondo-se a alegria da personagem ainda embalada pela voz de Lewis e dos outros instrumentos. Nesse instante, enuncia-se o primeiro estranhamento da primeira personagem. O saxofone vai revelando um lamento esquecido. Aos 3 min $52 \mathrm{seg}$, a personagem para e olha em direção ao horizonte para ouvir o lamentoso e agonístico som do saxofone de Coltrane.

Uma sucessão de planos apresentará uma segunda personagem trajando vestimentas de uma das diversas culturas africanas. As imagens da primeira personagem sem roupas opoem-se esteticamente a essa segunda personagem. Os tambores se intensificam a cada alternância de plano entre o homem livre e esse segundo demonstrando poder.

A segunda personagem nos faz lembrar-se da África com seus reinados. A alegria dessa personagem dançando bem-vestida é alternada gradualmente por planos em closed da primeira personagem que agora olha com uma expressão de suspeita para a câmera.

A cada alternância de plano, a primeira personagem se estranha ao se tocar, conscientizando-se a não ter mais aquele corpo. A segunda personagem em trajes de um rei africano também vai estranhando aquele homem livre. A primeira personagem não consegue demonstrar tanta alegria. Ao tocar-se, ainda tem esperança de ainda se reconhecer de acordo com a sua ancestralidade enquanto a segunda personagem continua dançando ao som dos tambores. Essa parece não ouvir o saxofone emitindo lamentos e dores.

Aos 4 min $46 \mathrm{seg}$, os planos da segunda personagem alternam-se com uma terceira personagem paramentada de acordo com um rei aparece e com uma expressão de julgamento daquela. A voz de Juno Lewis enuncia-se de forma lamentosa aproximando-se do saxofone de Coltrane.

A segunda personagem vai aos poucos perdendo a alegria. Essa sai de cena e em seguida a câmera fixa a tela toda em branco. A personagem caminha para trás com uma expressão de estranhamento e finalmente percebe o cenário todo branco a sua volta. A partir desse momento, o som do saxofone se torna mais potente do que os outros instrumentos chegando ao clímax de sua performance: afinal, a personagem está presa. 
A personagem em plongée1 está deitada no chão com os braços aberto. Procura uma saída e começa a andar de forma debilitada em direção ao lado esquerdo do enquadramento. Um corte passa para um novo plongée, onde Zózimo Bulbul em posição fetal, de frente, oculta o rosto com os próprios braços - onde avistamos braceletes brancos- e ao abri-los descobrimos que se trata de uma corrente branca. Ao tocar sob a superfície do território branco, ele faz diversos movimentos com os braços com intuito de sair daquele lugar. Tenta soltar os braceletes, revelando sua impotência. Movimenta o rosto de diferentes formas. Gira as pernas sobre o seu próprio eixo em círculos, enquanto alguns cortes com closes do rosto refletem dor e desespero.

A partir de 7 min o som do saxofone é tocado quatro vezes lembrando o apito dos tumbeiros. Esse som compõe junto com a agonia da personagem presa por uma corrente a opressão de ser retirada da liberdade e levada ao processo de escravização em outras terras distantes das suas origens. A personagem, antes reconhecedora de sua ancestralidade, condutora de sua cultura e de sua vida, vai aos poucos perdendo a consciência e entregando-se a loucura do estado de opressão.

Aos $8 \mathrm{~min}$, o saxofone se impõe sobre todos os instrumentos dando apenas a sentir a vibração dos tambores. As alterações de planos dos figurinos e dos movimentos sucedem situações dos modos de existência mais estereotipados do negro na sociedade brasileira: o lavrador, o jogador de futebol, o sambista, o pugilista, o ladrão e o pedinte.

A loucura continua a perturbar a mente da personagem que na atualidade continua escrava das elaborações dos seus opressores. E mesmo quando existe a possibilidade de ascensão social, representados em outro plano pelo violonista e pelo intelectual lendo um livro, as correntes continuam a aprisioná-lo. Não há terno branco capaz de retirar os braceletes de seu pulso.

Uma possível releitura desse condicionamento opressor mesmo após a abolição é o resgate da ancestralidade africana. Assim, a personagem vai abandonando cada uma das vestimentas brancas: paletó, camisa, calça, bermuda, sapato. Aliás, a bermuda branca é substituída por uma espécie de tanga preta. Apesar de não voltar a ser o que era antes, a primeira personagem tenta regressar a si. Assim, ela caminha em direção à câmera, levanta os braços e arrebenta as correntes. Olha novamente para a câmera sorridente e ao se aproximar, a própria figura, e inclusive as correntes, convertem-se em silhuetas contra o fundo branco e, então, curiosamente, ficam pretas. Toda a cor preta da pele de Zózimo ocupa a tela.

\section{EXPERIÊNCIAS MULTICULTURAIS E DECOLONIAIS COM O FILME ALMA NO OLHO NO CURSO DE PEDAGOGIA}

Após a exibição fílmica de Alma no olho aos estudantes e ao professor da disciplina, iniciamos o desenvolvimento da Análise criativa baseada em Bergala (2008) onde os participantes foram orientados a problematizarem sobre o que viram através dos elementos estéticos:

Estudante 1: Eu vi a história dos negros na diáspora, mas meio que assim, os estágios da diáspora.

\section{Professor: estágios históricos?}

Estudante 1: Acho que a partir do momento em que ele está lá na mãe África, que ele como negro começa a ter o contato com o homem branco e aí ele é sequestrado, e aí todas as etapas e parece que ele se liberta com a leitura de várias coisas ele consegue o contrário.

O diálogo entre a estudante 1 e o docente traz para a análise a questão de como o conhecimento é produzido. Ao lembrar-se do plano em Alma no olho,onde uma das personagens faz a leitura de um livro, a estudante 2 traz uma outra interpretação para compreender a origem dos conhecimentos para as populações afro-diaspóricas:

Estudante 2: Eu entendi um pouco diferente. Mesmo com a leitura, mesmo

\footnotetext{
${ }^{1}$ Plongée é um termo francês que significa em português "mergulho" e consiste em filmar um ator de cima para baixo. Tal técnica apresenta uma ideia de inferioridade do personagem em relação ao enquadramento total do plano.
} 
atingindo níveis do homem branco, ele [a personagem] permanece preso e só quando ele retorna para a cultura, que é o início da cultura africana, que ele consegue se libertar, mas enquanto ele está com a roupa branca ele permanece preso. A roupa branca me chamou atenção. A roupa branca pode ser uma metáfora. Enquanto ele permanece com a roupa branca ele permanece preso, mas quando ele volta para as raízes, quando ele retira aquela roupa, ele se liberta.

A estudante 2 analisou sobre os elementos totalmente brancos como símbolos ainda impostos pela cultura dominante mesmo quando os negros estão em posições elevadas da intelectualidade. Por isso, a graduanda considera a libertação da personagem possível apenas quando essa se despe das vestimentas brancas. A partir dessa análise, os estudantes questionaram-se sobre as possíveis liberdades mesmo quando negras e negros alcançam patamares elevados na sociedade brasileira:

Estudante 3: Mesmo que você esteja libertado numa sociedade eurocêntrica hegemônica, às vezes você está acorrentado socialmente no sentido de você estar preso a algo que não consegue te libertar em relação a isso. Mesmo que a corrente não esteja ali, mas às vezes eu me sinto acorrentada em alguns momentos.

A estudante 3 faz uma análise dos elementos fílmicos relacionando-os à sua existência. Ao mencionar a palavra "corrente", a graduanda faz um gesto com os pulsos cerrados, afastando-os um do outro dando-nos uma ideia de luta pela liberdade. Isso remete-nos a pensar sobre a realidade ainda predominante da academia tendo por referência os fundamentos majoritariamente eurocêntricos.

Assim, o fato de as correntes da personagem estarem ou não visíveis seria necessário para compreender se os negros alcançaram suas emancipações. Logo, a estudante 1, em diálogo com a estudante 3, remete essa problemática entre o conhecimento eurocêntrico e o diaspórico:

Estudante 1: E que você só conseguiria se libertar quando você voltasse ao seu local de origem.

Estudante 3: Mas às vezes o contato que você acha que vai te libertar te aprisiona muito mais

Ao olhar para a estudante 3, a estudante 1 reconhece na colega aquela que também busca se libertar. Para isso, é necessário voltar às origens e assim compreender como a personagem final de Zózimo Bulbul retoma sua integralidade quando ocupa toda sua existência sabendo quem é e de onde veio.

As questões levantadas esteticamente pelo filme por via da análise criativa trouxe-nos uma compreensão da corporeidade como um dos conhecimentos essenciais para os sujeitos reconheceremse inseridos nas temáticas emergidas por uma obra fílmica:

Estudante 3: Eu pensei muito na questão dos dias de hoje, sabe, pensar que ele [uma das personagens] fica numa agonia muito forte [faz gestos com os punhos fechados como se quisesse se libertar], acorrentado, ele passa por vários estágios até chegar ao estágio da leitura e por mais que a gente procure algo [olhar um pouco melancólico], a gente está sempre acorrentado [olhos para baixo], de alguma forma no sentido que sempre estão tentando nos silenciar, a gente tem que mudar por estarmos numa sociedade eurocêntrica, numa sociedade que tem uma padrão epistêmico hegemônico e a gente tenta se encaixar, se libertar disso, mas de forma que... a gente está preso nessa questão social [gesto de acorrentamento]. Se eu tenho uma coisa simbólica me prendendo, há algo que me prenda a isso, eu não consigo me libertar.

Mais uma vez, por meio de uma análise criativa, a estudante 3 traz as questões estéticas do filme para inter-relacionar à sua própria existência enquanto mulher negra por meio de sua corporeidade. Dessa forma, a estudante ao mesmo tempo narra o que viu em Alma no olho destacando os padecimentos 
e as tentativas de se libertar também estão presentes em si. Assim, ela reitera, mais uma vez, os gestos de acorrentar e libertar:

Estudante 3: Acho que a libertação é você se aceitar e [gestos circulares com mãos de baixo para cima tentando se libertar] nas suas origens onde tudo começa para você ter uma certa conscientização disso. Por mais que você tente se encaixar nesse padrão hegemônico, ele vai lá trás de onde ele veio tudo mais e consegue a libertação [gestos com as mãos representando a liberdade das correntes], mas acho que uma libertação só das correntes, eu não sei, dos pensamentos, das atitudes ainda está uma coisa liberta. Até hoje, ... uma sociedade que vive acorrentada em tudo. Trago isso muito pra hoje, procurando se encaixar porque, a gente acaba vendo que não é isso.

A reflexão da Estudante 3 também remete a verdadeira liberdade compreendida pela personagem final quando retira todos os elementos brancos e ocupa o último plano até que a tela fique toda preta. Além disso, a estudante problematiza sobre a verdadeira libertação não restrita ao corpo. Para ela, essa emancipação se efetivaria por meio do pensamento relacionado aos conhecimentos.

A análise criativa da estudante 3 , assim como as anteriores, problematiza a produção de epistemologias capazes de fundamentar historicamente como os corpos negros deveriam ser enunciados para poderem estar presentes em uma sociedade pós-colonial. Afinal, como nos lembra Mignolo (2003), mesmo com a apropriação de práticas teóricas das populações historicamente subalternizadas, ainda, os conhecimentos continuam dentro dos parâmetros ocidentais.

O professor da disciplina, ao continuar a proposta da análise criativa, também compreende diferentes formas de como Zózimo Bulbul pensou, pela estética do filme, em problematizar essa relação de dominação e a busca por algum tipo de liberdade:

Professor: Acho que nessa linha, o que me chamou a atenção foi o contraste da figura negra com o fundo branco. O tempo todo é engraçado que ele cria um cenário [olhos para cima e em seguida coloca as mãos para o alto como se tivesse criando algo], um fundo que você não vê o chão. A sensação é que ele está flutuando, como se faltasse um chão, um lugar para pisar, se firmar. [Faz um gesto com as pernas como se quisesse se estabilizar]... sem perspectivas. Uma opção dura porque o filme preto e branco reforça essa realidade o branco ou preto? Você não vê muitas gradações. E no final é quando ele rompe as correntes é que ele vai ganhando o primeiro plano [abre os braços e como se quisesse ampliar o plano mencionado] ele vai acabando com o fundo branco, né? Que vai escurecendo, escurecendo, escurecendo. Aí ele para com o fundo [paralisa os braços] branco.

Ao trazer as relações entre as cores brancas e pretas, o professor ressignifica-as por meio de uma análise criativa na qual o fundo branco, que compõe todo o cenário, remete a dominação de toda a perspectiva eurocêntrica. Todavia, a cor preta da pele de Bulbul contrapõe-se no sentido de existir e resistir. É interessante notar na expressividade do docente a capacidade de interpretar a estética do filme em seu próprio corpo. Dessa forma, o regente foi sensibilizado ao fazer sua análise abordando a perspectiva do próprio negro. Essa reflexão sinaliza a importância dos não negros em compreender as celeumas inerentes às populações afro-brasileiras e suas emancipações pelas formas como essas almejam serem vistas e ouvidas.

Ao reapresentar Alma no olho, foi proposto aos estudantes ainda por meio de uma análise criativa que eles se imaginassem co-diretores do filme. Nesse caso, foram questionamos quais outras escolhas estéticas eles fariam. A presença histórica foi uma das categorias mais enunciadas:

Estudante 5: Acho que falar da história da escravidão sem falar da perspectiva da mulher negra, acho que é importante, acho que eu acrescentaria isso. É uma parada que tem suas nuances, é diferente. Em relação à carga de trabalho não 
havia diferenciação e ainda tinha toda a questão sexual. Eu acho que eu acrescentaria isso [...] Acho que essa questão, a questão do sofrimento sexual, por exemplo, que elas sofreram muito, da igualdade do trabalho, que não havia diferenciação, eu acho que assim, às vezes se não fosse encenado por um homem, fosse por uma mulher, isso abarcaria até questões mais amplas em relação á escravidão. Ela sofreu mais do que o homem.

Ao lembrar-se da necessidade de uma escrita histórica fundamentada na trajetória das mulheres negras, o estudante 5 recordou sobre a importância de enunciar os processos opressores específicos ao gênero feminino negro. Ao questionar a ausência da mulher negra em Alma no olho, o estudante 5 problematiza uma das principais temáticas quando se trata das pedagogias decoloniais: a interseccionalidade. As intersecções de raça e gênero ampliam o espectro de produções epistemológicas sobre as populações negras. A problematização trazida pelo estudante nos fez pensar sobre a responsabilidade da universidade em fundamentar os currículos da formação docente com as questões raciais e suas relações inerentes ao gênero e à sexualidade.

Uma possível solução para que Alma no olho abarcasse as lacunas referentes às mulheres negras foi trazida pelo docente:

Professor: Eu acho que ele poderia se representar de uma forma que não fosse tão masculina. Mantendo... mantendo essa ideia de que ele é o único ator. $\mathrm{O}$ Zózimo é de uma época. O movimento Negro, muitos homens são acusados de ser machistas. No próprio movimento LGBT dizem em uma pesquisa feita acusou-se que os homossexuais masculinos acabam tendo suas questões privilegiadas. Eu acho que poderia ele representar uma feminilidade de alguma forma. Acho o filme um pouco pudico, porque mostra a bunda do cara, mas não mostra o pau do cara. Poxa, chegou até aqui. Achei que rolou uma autocensura. $[\ldots]$

Estudante 3: Acho que talvez se fosse uma mulher mostraria tudo.

Para o docente, a masculinidade se impõe sobre o filme, o que também pode ser entendido e fundamentado pelos próprios posicionamentos históricos cujas cinematografias negras ainda ficam restritos à produção de conhecimento do homem. Essas problematizações avançam por meios das escolhas estéticas ainda limitantes aos homens negros e às mulheres negras. Afinal, segundo o professor, não haveria problema em mostrar o corpo todo de Zózimo se ele estava exatamente exercitando imageticamente a naturalidade da negritude contra os estereotipos.

A estudante 3 complementa as ideias apresentadas pelo docente quando deixa em dúvida se caso as personagens fossem mulheres, as genitálias provavelmente seriam mostradas. Ou seja, a graduanda relembra a contrução histórica onde foi produzida uma hiperssexualidade da mulher negra para ser exposto.

Entre ocultamentos do corpo negro masculino e exibições do corpo negro feminino se evidencia historicamente ainda uma preocupação estética voltada a atender as demandas das imagens aos quais as negras e os negros ficaram condicionados a não serem vistos de forma natural e íntegra às suas existências. Dessa forma, a problematização dessa corporeidade, oculta e visível, se relaciona a uma História ainda desconhecida e necessária aos currículos da formação docente e universitária.

\section{DO PLANO DO FILME AO PLANO DE AULA}

Após as análises criativas, solicitamos aos estudantes a produção de planos de aulas a partir de um plano fílmico de Alma no olho. A proposta de pensar o plano de aula pelo plano do filme remete-nos a uma relação entre o cineasta e o professor.

Da mesma forma como o cineasta, na maioria das vezes, roteirriza no papel uma primeira ideia da composição fílmica, o plano de aula tem também uma constituição imagética a partir dos elementos necessários à docência para compor uma aula: o público estudantil, a temática da aula, as formas como os conteúdos serão trabalhados, as formas como os estudantes serão atravessados pelos conhecimentos 
e o processo avaliativo a ser adotado.

A princípio, a atividade se realizaria dividindo a turma em grupos de 4 estudantes, mas o docente sugeriu que o plano de aula fosse feito com todos os estudantes presentes, pois isso ajudaria os graduandos de bacharelados a compreender como fazer o planejamento do tema de uma aula. $O$ interesse do docente em orientar a atividade era feita por meio de perguntas aos estudantes para saber como eles consideravam a melhor forma de desenvolvê-la.

Ao contar com aceite dos estudantes para fazerem a atividade em conjunto, o docente sugere o registro do plano de aula na lousa branca, permitindo a todos a visibilidade das ideias. Aqui fazemos uma analogia do docente com um cineasta ao almejar visibilidade das imagens na tela por todos. Por meio da Pesquisa-ação, o regente, nas palavras de Thiollent e Colette (2014, p. 213) relacionou "o conteúdo do ensino; o grupo; a didática; a comunicação; a melhoria da aprendizagem dos estudantes".

No processo de registro dos tópicos do Plano de aula, o docente questionava aos estudantes como o documento poderia ser construído, baseando-se nos conhecimentos curriculares trabalhados na disciplina. Dessa forma:

[a] atitude de pesquisar e agir em relação ao conteúdo e ao ambiente de ensino abre espaço para a criatividade do educador tanto quanto dos educandos, que deverão buscar as melhores formas de acessar e de processar os conteúdos de ensino face à realidade em que se situam. Como sujeitos do processo educativo, docentes precisam acessar, do campo múltiplo de possibilidades pedagógicas, aquelas mais identificadas com suas possibilidades e com as potencialidades e necessidades da comunidade discente. (THIOLLENT, COLETTE, 2014, p. 215)

A potencialidade da produção do plano de aula foi reiterada pela participação de estudantes de diferentes cursos de graduação, onde foi possível perceber como a formação de cada um deles contribuiu para a confecção do planejamento do documento trazendo aspectos multiculturais de várias áreas do conhecimento e também com perspectivas decoloniais quando foram sendo pensados temas, objetivos, conteúdos, materiais e recursos mais próximos da realidade de alunos das classes populares. Ao final da atividade, o plano de aula foi apresentado da seguinte forma:

Plano de Aula

1)Público Alvo = Educação de Jovens e Adultos

Quantidade de alunos $=+-25$ alunos

turno: Noite

bairro: Centro da Cidade

Município: Rio de Janeiro

2) Objetivos:

*Analisar a perspectiva histórica do filme;

*Pensar a diáspora africana;

* Refletir sobre a poética do filme (Como ele foi feito);

3) Conteúdo:

História: Colonização do Brasil e seus desdobramentos

Artes: Gestalt

Geografia: Brasil -Europa -África

4) Estratégia/ Material

Pensar o filme na sua integralidade 
Em roda, será pedido que selecionem um fragmento do filme para expor a interpretação do filme.

Antes, porém, será solicitado que selecionem dois fragmentos em que o personagem

$1^{\circ}$ ) aparece com vestimentas étnicas acadêmicas apropriando-se do saber hegemônico;

\section{$2^{\circ}$ ) personagem de costas e acorrentado}

A escolha do bairro onde esse possível Plano de Aula pode ser aplicado é de uma escola pública localizada no Centro do Rio de Janeiro. Esse território representa um espaço transitório entre os bairros periféricos e os de médio/alto poder aquisitivo. Os estudantes explicaram que pela Central do Brasil, muitos desses trabalhadores passam todos os dias rumo aos seus postos de trabalho, tanto ali mesmo ou em direção aos bairros nobres da Zona Sul carioca. Não estabelecem necessariamente uma relação com aquele espaço. Ao escolher esse território como possibilidade de pensar a aplicabilidade do Plano de aula, estabelece-se uma ideia de trazer à tona implicações entre aqueles que compõem um processo histórico e político, mas que não foram formados para pensar sobre ele.

Quanto aos objetivos, os graduandos almejam desenvolver conhecimentos referentes à trajetória histórica das populações afro-diaspóricas presente no filme Alma no olho. Quanto à diáspora africana, compreendemos a urgência em construir outros conhecimentos sobre os quais se inscreveram os conhecimentos ancestrais da África no Brasil. Em relação a poética do filme, a categoria estética é colocada como uma das formas para possibilitar a compreensão das escolhas do cineasta por meio de sua própria corporeidade. O estudante 5 entendeu após a elaboração do plano de aula a História presente na própria corporeidade de Zózimo Bulbul.

Ao que se refere ao conteúdo, os estudantes optaram por desenvolver uma perspectiva interdisciplinar em que as temáticas estão presentes principalmente pelas orientações das Diretrizes Curriculares Nacionais para a Educação das Relações Étnico-Raciais e para o Ensino de História e Cultura Afro-brasileira.

No caso do conteúdo de História, ao indicarem o tema da colonização e seus desdobramentos, os estudantes explicaram a importância de compreender os subjugamentos ainda contínuos quando os negros ficam restritos a alguns papéis como o jogador de futebol, o sambista, o pugilista ou limitados às perspectivas de conhecimentos eurocêntricas.

Com relação às Artes, o grupo optou por desenvolver as perspectivas da Gestalt, um conceito Alemão sem tradução específica para o Português, e significa a Psicologia da Forma. Essa teoria aborda a construção de diferentes imagens pelo cérebro, bem como as formas como são processados e reorganizados na estrutura psíquica. Nesse caso, relacionar a Teoria da Gestalt às Artes para os licenciandos possibilitou uma forma de pensar sobre as possíveis interpretações estéticas presentes em uma imagem. Assim como os alunos questionaram se a pulseira estava ou não nos pulsos de uma das personagens durante $o$ ato de ler, pode-se vislumbrar ora uma suposta emancipação, ora novas formas de opressão.

Com relação ao conteúdo de Geografia, os participantes inter-relacionaram temáticas referentes ao Brasil, Europa e África com o intuito de compreender como esses três territórios foram enunciados no filme. Para a estudante 2, o continente africano era essa constante presença desde o nascimento da primeira personagem ao reconhecer suas corporeidade e exaltá-la com alegria. A Europa estava enunciada na forma como após os processos de escravização e pós-colonização os negros vão se apropriando da cultura eurocêntrica, impossibilitando suas liberdades, como no caso das vestimentas brancas e do livro de cor branca. A referência ao Brasil foi compreendida pelos estudantes enquanto espaço diaspórico restrito aos estereótipos ou as práticas sociais aceitas pelo eurocentrismo como no caso dos planos referentes à intelectualidade, sem desenvolver a plena emancipação humana.

Na última parte, o grupo apresentou como estratégia o desenvolvimento a partir de planos fílmicos de Alma no olho. A ideia de um plano de aula voltado aos estudantes da EJA deveriam selecionar dois 
fragmentos. O primeiro em que ele [a personagem] aparece com vestimentas acadêmicas fazendo referências ao plano em que uma das personagens está lendo o livro de cor branca. A escolha desse plano tem a ver com as problematizações dos estudantes sobre o conhecimento emitido pelo livro enquanto possível emancipação para as populações afro-diaspóricas. O segundo plano do personagem acorrentado reitera a opressão sofrida em variados momentos históricos quando os negros africanos são sequestrados de suas terras originárias.

\section{CONSIDERAÇÕES FINAIS}

A pesquisa voltada para a produção de conhecimentos produzidos pelo cinema negro no curso de Pedagogia de uma universidade federal possibilitou-nos por meio da Pesquisa-ação e da Análise criativa evidenciar a capacidade do regente e dos estudantes em inserirem-se nos saberes emergidos ao contactarem o filme Alma no olho.

A corporeidade foi presentificada pelos participantes a partir de suas reflexões, levando-os a exercitar a sensibilidade externalizada em seus rostos e gestos. Dessa forma, muitos sentiram a necessidade de não apenas falar sobre as impressões estéticas, mas trazer com seus corpos as interpretações de dores e sofrimentos transmitidos pelo filme como foi da estudante 3 do regente da disciplina.

A estudante supracitada trouxe para sua análise as imagéticas do filme relacionadas à sua vida. Essa ideia foi reiterada pela corporeidade da licencianda ao analisar criativamente o filme por meio de expressões corporais e faciais. Outros estudantes compreenderam o subjugamento da mulher negra bem como dos aspectos inerentes ao feminismo negro como um dos principais conhecimentos a serem problematizados, caso os estudantes fossem co-diretores da obra fílmica, com o intuito de evidenciar questões específicas desse grupamento social no processo histórico das populações afro-diaspóricas.

A corporeidade também foi utilizada nas análises do professor responsável pela disciplina buscando expressar-se e trazer para si novas possibilidades interpretativas das imagéticas negras. Em seu caso, o docente propiciou a si aprendizagens capazes de ter por referências a estética proposta por Bulbul capazes de ressignificar seu posicionamento enquanto homem branco e intelectual da academia.

A referência no cinema bulbuliano também fez-nos observar a sensibilidade do docente para conduzir a aula sobre o cinema negro considerando a obra fílmica como o conhecimento estético para fundamentar os currículos e as didáticas da disciplina. Dessa forma, também foi possível vislumbrar essa característica na maneira como o professor buscou direcionar os estudantes, cada um de acordo com a sua formação, a participarem ativamente da construção do plano de aula. Nos caminhos da Pesquisaação, o docente desenvolveu "práticas e relacionamentos condizentes com uma perspectiva emancipadora de sua atividade profissional, assim como dos indivíduos, dos grupos, comunidades e contextos de sua atuação" (THIOLLENT, COLETTE, 2014, p. 214)

Dessa forma, as colocações e questionamentos dos estudantes foram melhor sistematizados ao construírem o plano de aula a partir dos planos fílmicos de Alma no olho (1973). Ao inter-relacionarem diferentes saberes enunciados pelo filme, os graduandos planejaram uma aula cujo público e o espaço onde essa escola seria localizada podem apresentar as melhores possibilidades para o desenvolvimento de novos conhecimentos por meio de diferentes áreas do conhecimento que vislumbram a participação de futuros estudantes da educação básica de forma diversa, plural e multicultural.

\section{REFERÊNCIAS}

ALMA no olho. Direção: Zózimo Bulbul. Rio de Janeiro - RJ, 1974. 12 min

BARBIER, R. A Pesquisa-Ação. Brasília: Liber, 2007. Tradução de Lucie Didio.

BERGALA, Alain. A hipótese cinema. Pequeno tratado de transmissão do cinema dentro e fora da escola. Rio de Janeiro: Booklink, 2008.

BRASIL. Base Nacional Comum Curricular. Brasília: MEC, 2017. Disponível em:

http://basenacionalcomum.mec.gov.br/images/BNC C_2odez_site.pdf. Acesso em: 22 de dezembro de 
2017.

BRASIL. Diretrizes Curriculares Nacionais para a educação das Relações étnico-raciais e para o ensino de História e Cultura Afro-Brasileira e Africana. Brasília, 2003.

BRASIL. Ministério da Educação. Proposta para Base Nacional Comum da Formação de Professores da Educação Básica. 2018b.

CANEN, Alberto; IVENICKI, Ana. Metodologia da Pesquisa: rompendo fronteiras curriculares. Rio de Janeiro: Editora Moderna. 2016.

CANEN, Ana. A pesquisa multicultural como eixo da formação docente: potenciais para a discussão da diversidade das diferenças. Ensaio, v.16, n.59, p. 297-308, abr/Jun. 2008.

GOMES, Nilma Lino. Relações étnico- raciais, educação e descolonização dos currículos. Currículo sem Fronteiras, v.12, n.1, p. 98-109, Jan./Abr. 2012.

GOMES, Nilma Lino; JESUS, Rodrigo Ednilson. As práticas pedagógicas de trabalho com relações étnicoraciaisna escola na perspectiva da Lei 10.639/2003: desafios para a política educacional e indagações para a pesquisa. Educar em Revista, v. 47, p. 19-33, jan/mar. 2013.

HALL, Stuart. Da diáspora: Identidades e Mediações Culturais. Belo Horizonte: Editora UFMG, 2003. HOOKS, bell. Ensinando a transgredir: a educação como prática da liberdade. Tradução de Marcello Brandão Cipolla. São Paulo: Editora WMF Martins Fontes, 2013.

HOOKS, bell. Olhares negros: raça e representação. Tradução de Stephanie Borges. São Paulo: Elefante, 2018.

MACEDO, Elizabeth; RANNIERY, Thiago. Políticas Públicas de currículo: diferença e a ideia de público. Currículo sem Fronteiras, v. 18, n. 3, p. 739-759, 2018.

MIRANDA, Cláudia. Currículos decoloniais e outras cartografias para uma educação das relações étnicoraciais: desafios político-pedagógicos frente à Lei n. 10.639/2003. Revista da ABPN, v. 5, n. 11, jul.- out, p. 1.00-118, 2013.

MIRANDA, Cláudia; RIASCOS, Fanny Milenna Quiñones. Pedagogias Decoloniais e Interculturalidade: Desafios para uma Agenda Educacional Antirracista. Educação em Foco, Juiz de Fora, v.21, n.3, set. / dez., p. 545- 572, 2016.

THIOLLENT, Michel Jean Marie; COLETTE, Maria Madalena. Pesquisa-ação, formação de professores e diversidade. Acta Scientiarum. Human and Social Sciences Maringá, v. 36, n. 2, Jul-dez., p. $207-216,2014$. WALSH, C. Interculturalidade Crítica e Pedagogia Decolonial: in-surgir, re-existir e re-viver. In: CANDAU, V. M. (org.) Educação intercultural na América Latina: entre concepções, tensões e propostas. Rio de Janeiro: 7Letras, 2009.

Este obra está licenciado com uma Licença Creative Commons Atribuição-NãoComercial 4.0 Internacional. 